\title{
Why A Medical Career? What Makes Sudanese Students to Join a Medical College and Pursue a Medical Career?
}

\author{
Ismat Mohammed Mutwali ${ }^{1, *}$, Aisha Ibrahim A Omer ${ }^{1}, \&$ Sadigh Mohammed Abdalhalim ${ }^{2}$ \\ ${ }^{1}$ Faculty of Medicine, Alzaeim Alazhari University, Khartoum Bahri, Sudan \\ ${ }^{2}$ Department of Psychology, Faculty of Arts University of Khartoum, Sudan \\ *Corresponding author: Alzaeim Alazhari University, Khartoum Bahri, Sudan. E-mail: ismatwally@yahoo.ca
}

Received: January 4, $2015 \quad$ Accepted: February 5, 2015 Online Published: March 27, 2015

doi:10.5430/wje.v5n2p19 URL: http://dx.doi.org/10.5430/wje.v5n2p19

\begin{abstract}
Introduction:

Career selection and decision to pursue a medical career is a multi factorial process. It is influenced by the personal capabilities and the available resources as well as the social, educational, economical and cultural factors. Sudan is one of the African countries with a high number of medical colleges and an increasing number of Sudanese students are joining the medical colleges each year.
\end{abstract}

Aim and objectives:

The aims of the present study were to study and compare the motives and reasons for joining a medical college and pursuing a medical career, among the newly admitted Sudanese medical students.

Methods:

A cross sectional survey was implemented, in eight medical colleges (four private and four public colleges) in Khartoum. A semi structured questionnaire was used to collect data from the subjects to investigate and compare the reasons and motives for choosing a medical career.

Results:

1556 students responded to the questionnaire (86\%). 50.9\% of them were admitted on private account; and $63.7 \%$ students were from public colleges; and $61.8 \%$ were female. The highest ranked reason for choosing a medical career was the altruistic reason (78.1\%) and the lowest reason was the personal ambition (17.9\%). $71.2 \%$ of the students were influenced by the family to joining a medical college. $11.9 \%$ of the students joined the medical colleges against their desire. There were differences between the publicly admitted and privately admitted students.

Discussion:

The reasons and motives of the Sudanese medical students, for selecting a medical career, are comparable to other international studies.

Keywords: career choice; reasons and motives; newly admitted medical students; Sudanese medical students

\section{Introduction and Background}

Career choice is a process that matures through many years and it is based on early aspiration, realistic selection and personal capabilities as well as labor market and the available resources. The final choices of career selection represent the results of compromise between personal ambition, capabilities, values and the available opportunities(Sherril, 2004) Social factors, intelligence, race, gender and family influence represent the major influential factors for the educational and career choices. Financial factors also play a role in career choice. (Sherril 2004, David etal., 1990, Gillies etal., 2009, Diwan etal., 2013)

Student's parents are the individuals most influencing their decision to join an educational course. The mother or the female guardian has Esters LT, Bowen BE. (2004 more influence than the father or male guardian to choose a specific professional course. (Esters \& Bowen, 2004, Mc Harg, 2007) Events and experiences that an individual 
passes through, also have influence in selecting a particular educational programme.(Esters \& Bowen, 2004) In 1971 Bandura hypothesized that " if an individual believes that he/she has the skills needed for a demanding occupation and that practising that occupation will bring success in life, he/ she will work hard with education and training " (Mc Harg, 2007; Bandura, 1986) Krumbolz and colleges used the ideas of Bandura to design a model of career decision making "The social learning theory of career decision making" This theory was developed in 1990 to address the question: Why people join a particular educational course and pursue a specific career. (Krumboltz, 1976)

The social learning theory of career decision making postulates that there are four sets of factors that can influence career choice: 1- genetics and cultural factors which include: race, gender, physical appearance and characteristics; these inherited qualities can affect the individual's ability to select a specific job. 2- The environmental conditions and events which include: social, cultural, political and economical forces as well as natural factors and resources. These factors are out of control of the individuals. 3-The learning experiences which may be either instrumental or associative that can results in occupational stereotypes. 4- Task approach skills which indicate the individual's standards of performance, work's habits and emotional responses. As a result of interaction of these four influencing factors, peoples form beliefs that will affect the individual's aspiration choices and actions.(Krumboltz etal., 1976; Mitchel etal., 1999)

Sudanese medical education is dating back to 1924 when the first medical school in Sudan, the Kitchener school of medicine was established; that school is know the faculty of medicine University of Khartoum. Up to 1978 there were 3 medical colleges in Sudan. (Fahal, 2007) During the nineties of the last century a large numbers of universities and medical faculties were established, both at the private sector and public sector, due to the revolution of the higher education in Sudan. The total number of faculties of medicine in Sudan up to 2005 were 29 medical colleges eight of them were private.(Fahal, 2007; Ministry of Higher Education and Scientific Research, 2008) During 2013-2014 academic-year there were 33 faculties of medicine in Sudan; out of these 21 were public medical faculties and 12 private ones. In Khartoum state there were ten private and seven public faculties of medicine.(Ministry of higher education and scientific research. Directorate of admission, evaluation and authentication of certificates, 2013) Admission to public medical colleges in Sudan is centralized and is based on the qualifying secondary school examination scores (percentage). Admission into private medical faculties is often dependent on relative academic merit but more on the ability of the students to pay the education fees. In all the public medical colleges there is a number of students who are admitted on private bases (they pay education fees). These students usually obtained a lower score than the common centralized admission criteria (percentage).

Public faculties admit to a percentage of their seat on private basis .i.e. an $\mathrm{A} \%$ of their yearly admission is given to student with a fairly high scores, but who's scores fell short of gaining seats in the national public admission .The admission here is also through the national admission committee and it is open to these students provided they agree to pay the fees prescribed by the university to which the faculty belongs, so even in this type of admission there is a competition and the order of academic merit is observed.

The justification of this policy of private admission to public medical faculty is to increase the income and resources of the public medical faculties. Another justification for this private admission policy is to give chance for students from less developed regions of the country to study medicine and contribute in improving health services in their underdeveloped regions. (Fahal, 2007) The public medical faculties in Khartoum State are national; they admit students from all over the Sudan.

The admission to private faculties is also run in its first stage by the national admission committee. Students apply through this committee to the private faculty. The committee observes that merit is observed; a student with a high score is given the seat since all applicant agreed to pay the prescribed fee. The national admission committee runs a second admission after studying the overall outcome of the first admission. The second admission gives students and faculties the chance of either changing their choice (mind) or filling vacant seats. If after this two admissions a private faculty has still some vacancies the university or faculty is given a permission to fill these vacancies through their own admission board.

If data can be obtained about reasons for joining a faculty of medicine, it will help to develop strategies that address them and identify or assign interventions that may consider these reasons and put plans for higher education. Themes that may ensue from the different students` motivations may have impacts on medical students learning and on their future practice. Today`s students have different work priorities and personal motivations which may impact their learning. (Gillies, etal., 2009; Vanderveen, \& Bold, 2008) Health system administrators and policy maker should consider these motives and reasons during their planning.

The aims of the present study were to study and compare the motives and reasons for joining a medical faculty and 
pursuing a medical career, among the newly admitted Sudanese medical students.

\section{Methods}

A cross sectional survey of the first year Sudanese medical students during 2013-2014 academic-year. Eight medical faculties were included in the study (four public and four private faculties of medicine), in Khartoum State, Sudan.

A semi structured questionnaire was designed containing the most possible motives and reasons for joining a medical faculty. The motives and reasons were collected from the literature and discussion among the research team. The questionnaire also included a part dealing with the socio economical status of the students and their families as well as whether the students were admitted on public bases or private account. After extensive discussion among the research team 50 possible reasons were agreed upon. These reasons were grouped in five common groups: 1-Desire (personal ambition) 2- Financial rewards (pecuniary interest) 3- Familial (Parents desire or previous experience) 4Social reasons (prestigious profession, altruistic reasons) 5- Educational reasons (enjoying science learning, cognitive challenge of learning medicine and high scoring marks \{percentage\} in the school certificate examinations). The questionnaire was reviewed for content and validity, by a panel of experts of 4 staff members of the faculty of medicine of A A U and 5 staff- members of the department of psychology, faculty of arts of Khartoum University. The questionnaire was also pilot- tested using 25 first- year medical students from A A U. Some modifications were done after reviewing and testing, before the final administration.

The study was implemented during December 2013 and January 2014, within 3 months after the students started their medical studies. A written request was send to all deans or administrations of the selected faculties inviting them for participation. One private faculty declined participation so another private faculty was invited and agreed to participate. The requests included the purpose of the research and asking permission to address the students for administration of the questionnaire. A date and time was assigned for questionnaire's administration, usually at the end of a scheduled lecture at the lecture theatre. One or more of the research team, together with assistant researchers were present during administration of the questionnaire in all the eight medical faculties, to explain the purpose of the survey and to invite the students to participate voluntarily in the survey and assuring the participants the anonymity of the information collected. The survey was in the Arabic language, because the first-year medical students were novices and their English language was not so good to understand the content of the survey and answer the questions transparently.

\subsection{Data Analysis}

The data were analysed for the descriptive statistics using SPSS version 15. Frequency, percentage, and mean \pm SD were determined. Independent $\boldsymbol{t}$ test was used for comparing two independent variables, and one way ANOVA test was used for comparing more than two variables. A $P$ value $\leq \mathbf{0 . 0 5}$ was set to be significant.

\section{Results}

The total number of students admitted to the eight medical faculties included in the study was 1808 students. The number of the students who participated in the study was 1556 students; that means a response rate of $86.1 \%$. Out of the total number of the admitted students, 992(63.7\%) were admitted to the public faculties of medicine. About half of the participants $(50.9 \%)$ were privately admitted students, either within the public or private medical faculties. Female students represented $61.8 \%$ of the participants. Age range of the participants was between 15 and 21 years and $83.5 \%$ of the participants were 18 -year-old or less. Regarding the family income $71.8 \%$ of the participants students were depending on the father's income, and $20.3 \%$ of the students were depending on both the mother and father's income. Only $3.5 \%$ of the students were dependent on the mother's income. Out of the total number of the participant students, $77.4 \%$ joined the medical faculties following their success in the Sudanese school certificate examinations, and $22.6 \%$ obtained a foreign school certificate. The parents` employment is showed in table 1.

Table 1. Illustrates the Students`Parents`Employment

\begin{tabular}{|c|c|c|}
\hline Employment & Father $\quad(\%)$ & Mother \\
\hline Free business & 34.3 & 2.8 \\
\hline Governmental employed & 52.1 & 27.3 \\
\hline Private employment & 6.6 & 0.9 \\
\hline Retired & 3.8 & --------- \\
\hline Not employed & 3.3 & $68.9 *$ \\
\hline
\end{tabular}


*House wives.

The motives and reasons of the newly admitted medical students are shown in table 2 . Some the reasons were grouped together for more clarification

Table 2. Reasons and Motives of the Sudanese Medical Students to Study Medicine

\begin{tabular}{|c|c|}
\hline Reasons and Motives & Responses $(\%)$ \\
\hline \multicolumn{2}{|l|}{ Desire and personal ambition } \\
\hline Desire to study science and be scholar & 28.75 \\
\hline I enjoy studying science and to pursue in this field & 9.1 \\
\hline I find myself in studying medicine & 22.0 \\
\hline Desire to make change in the medical field & 19.7 \\
\hline Personal real desire to study medicine and be a doctor & 17.9 \\
\hline \multicolumn{2}{|l|}{$\begin{array}{l}\text { Financial reasons and rewards } \\
\end{array}$} \\
\hline The high income of my family was the cause of joining a medical college & 72.6 \\
\hline The needs of my family obliged me to choose the medical career & 53.1 \\
\hline The high income of the doctors was my reason to join a medical faculty & 68.7 \\
\hline Medical profession will place me in a high financial status & 56.6 \\
\hline Medical career will secure me a good income & 50.8 \\
\hline Studying medicine will enables me to establish private medical business & 46.2 \\
\hline Being a doctor will help me to help my family & 43.9 \\
\hline Graduates of the medical colleges will have a secured job after graduation & 39.2 \\
\hline Doctors will have a higher opportunities to find job abroad & 35.8 \\
\hline \multicolumn{2}{|l|}{ Familial influences and reasons } \\
\hline Previous experience with a family member or a relative & 71.2 \\
\hline One of the family members is a doctor & 69.4 \\
\hline Mother desire & 56.6 \\
\hline Desire to provide good health care to family & 43.5 \\
\hline \multicolumn{2}{|l|}{$\begin{array}{ll}\text { Social reasons } \\
\end{array}$} \\
\hline Desire to help others (altruistic reasons) & 78.1 \\
\hline Influence by others (society and school mates) & 76.6 \\
\hline Prestigious profession & 56.6 \\
\hline Influence by a role model Physician & 53.7 \\
\hline Doctors are respected by the whole society & 40.75 \\
\hline Influence by media (TV series and programmes) & 38.7 \\
\hline \multicolumn{2}{|l|}{ Educational influences } \\
\hline Encouragement I find from my school teachers & 75.3 \\
\hline The high marks (percentage) that I obtained in the school certificate examinations & 64.7 \\
\hline Medical profession is the place where I find the scientific challenges & 33.0 \\
\hline
\end{tabular}

Some of the reasons were grouped together for clarifying the results and avoiding confusion

Some of the participant students $(11.9 \%)$ joined the medical faculty against their own desire (they were forced by family), and $9.5 \%$ of the students joined the medical faculty against their family`s desire, (9.8\% from the public admission group and $13.9 \%$ from the privately admitted students).

The only group of reasons, where there was no significant difference between the students who have public admission and those who have been admitted on private account was the desire and personal ambition group $(\boldsymbol{P}=0.227)$ table 3 .

There were significant differences, between the students who have been admitted after passing the Sudan secondary school certificate and those who obtained a foreign secondary school certificates, in the financial and social reasons $(\boldsymbol{P}=0.013,0.000$ respectively). A significant difference was also found between female and male students in the social, desire and ambition and financial of reasons $(\boldsymbol{P}=0.05,0.000,0.000$ respectively). The parents jobs had no significant effect on the reasons of pursuing a medical career. 
Table 3. Illustrates the Differences between the Publicly and Privately Admitted Students Regarding Their Motives and Reasons to Pursue a Medical Career (Sudan 2014)

\begin{tabular}{lllllccc}
\hline Reasons & \multicolumn{3}{c}{ Public admission group } & \multicolumn{3}{c}{ Private admission group } & $P$-Value \\
\cline { 2 - 8 } & No & Mean & SD & No & Mean & SD & \\
\hline & 764 & 16.91 & 1.895 & 792 & 17.03 & 2.1129 & 0.227 \\
Financial Rewards and reasons & 764 & 14.40 & 2.7563 & 792 & 14.92 & 2.9155 & 0.000 \\
Familial influences and reasons & 764 & 13.61 & 1.7174 & 792 & 13.88 & 1.7131 & 0.002 \\
Social reasons & 764 & 11.80 & 1.6369 & 792 & 12.09 & 1.7861 & 0.001 \\
Educational influences & 764 & 14.93 & 2.1280 & 792 & 14.52 & 2.2398 & 0.000 \\
\hline
\end{tabular}

\section{Discussion}

We selected the structured questionnaire for collecting our data because our participants were the novice students of the first year, and for the relative easiness of this format compared to focus group discussion(FGD) for establishing the preliminary themes then the final themes followed by transcription. Gillies et al used the FGD method and established 8 themes (Gillies etal, 2009). We grouped our possible motives and reasons for pursuing a medical career into 5 groups, because we did not investigate the power of influence and relationship themes established by Gillies, and we included the previous experience into the familial reasons. The established 5 groups were: 1- desire and personal ambition which include motives or reasons related to the personal enjoyment of studying science or biology or to the challenge of exploring the human body function and structure, and reasons like pure desire to study medicine. 2- Financial rewards and reasons like high family income, the relative high income of the doctors, secured job, high opportunity of finding a job abroad. 3-Famillial influence; personal or family member previous experience, influence of parents especially the mother, desire to help family.4-Social reasons included the altruistic reasons, influence by community or school mates, prestigious profession, 5-Educational reasons; encouragement by school teachers, high marks( percentage) obtained in secondary school certificate examinations, desire to pursue an academic career. The higher ranked reason for pursuing a medical career for Sudanese students was the social reasons of helping other $(78 \%)$ and the lowest ranked reason was personal ambition $(17.9 \%)$.

Comparing the reasons cited by the Sudanese beginning medical students and those cited by United Kingdom students, (Maudsley etal., 2007) we found that the most common reason that attracted students to medical career in UK was the personal ambition and enjoying studying medicine (51.3\%); while in our study these reasons were cited by $29 \%$. The altruistic reasons were mentioned by $78 \%$ of our students and by $40.3 \%$ of the United Kingdom students. In a Finish study cited by Farrokhi Khajeh (Farrokhi Khajeh, etal., 2014) a majority of the medical students stated that helping others, job opportunities, prestigious profession and previous school achievement were the main reasons for pursuing a medical career. (Farrokhi Khajeh, etal., 2014) McHugh reported in an Irish study that 97\% of the medical students said that helping other is the main reason for choosing medicine as career, but the financial rewards were cited by male students more than females. (McHugh etal, 2011) Maudsly attributed the lower rank of the altruistic motives for selecting a medical career to the early professional responsibility and experience of the investigated students. Likewise we can attribute the high rank of the altruistic reasons to the enthusiasm of our students to serve their community. Some reports stated that the altruism of the new medical students wanes as they progress through their medical studies.(Maudsley, etal, 2007; Dambisya, 2003; Crandal, 1993) To days medical students start their medical studies very enthusiastic and willing to help others, but without scarifying their personal life. The financial rewards as reasons for pursuing a medical career are well documented.(Sherril, 2004; David etal., 1990; Gillies etal., 2009; Diwan etal, 2013; Mc Harg, 2007). This finding in our study was expected because of the limited resources of a developing country and the high rate of unemployment within other professions.

The statistical differences between the students who obtained Sudan school certificate and those who obtained foreign school certificate, is due to the fact that $77.4 \%$ of them completed their secondary school according to Sudanese syllabus. Female students during the last decades predominated the admission to the higher education in Sudan (more than $60 \%$ in our study) and in other countries.(McHugh, 2011) This finding can explain the difference found between female and male students in our study. The low percentage of students who expressed that the personal desire was the reason for pursuing a medical career may be due to their personal and families 'desire seeking the prestigious and /or the financial aspect of medical career.

Secondary school teachers' support and influence played a positive role in a good proportion of our students to pursue medical career (75\%). Contrary to the surprise expressed by McHarcg etal for the lack of support and encouragement of the school teachers for their students to join a medical faculty. Family influence is a major factor 
for choosing a medical career and it counter act the disappointment caused by the school teachers.(Mc Harg, 2007) The family support and encouragement should be directed to those students who have a personal desire for studying medicine, but not to force them to join a medical college against their desire. The finding that $11.1 \%$ of the Sudanese students study medicine against their desire (forced by family) can support our opinion that some of the Sudanese families send their offspring to study medicine just for the prestigious aspect of the medical career. Family pressure to pursue a medical career was cited by studies from Iran, Australia and other countries. (Farrokhi Khajeh, 2014; McHugh, 2011; Kim, 2013; Marley, 1999)

Maudsly cited odd answers: "Unfulfilling other career"(1\%) and "was not an active choice of mine"(1\%). Kim reported that $13 \%$ of the investigated Korean students were not interested in studying medicine. (Kim, 2013) In our study there were $11.1 \%$ students chose the medical career against their personal desire and $9.5 \%$ of our students selected the medical career against their family's desire. This finding of our study may explain the reasons why some of the Sudanese female doctors leave the medical profession after getting married. (Fahal, 2007)

Our study was conducted in 8 faculties of medicine in Khartoum, which represents about one fourth of the medical faculties in Sudan. However, both the public and private Sudanese medical faculties in Khartoum are national i.e. they admit student from all over the Sudan; this fact and the high response rate $(86 \%)$ may minimize the selection bias and gives weight to our results. Students from other medical faculties from others parts of the Sudan may have different reasons and priorities that may determine their career choices. The results of our study reflect the Sudanese students ' perspectives and it should be interpreted within its context, because it is affected by the health care system and its standard. However, our findings are still comparable with others` findings.

Future studies could focus on investigating the same cohort of students at their final year of medical courses to see whether their career choices were maintained or some other factors (clinical exposure, role model, life style) have made changed.

\section{Conclusion}

Our findings provide more evidences of the important factors among the Sudanese medical students, for choosing a medical career. These factors can be used by medical educationalists for curriculum and professional development. The policy makers and administrations should consider the financial rewards in their planning. Further evidences and support has been added, from a developing country, to the literature that students' decision to pursue a medical career is a multi factorial process.

\section{Acknowledgements}

The authors would like to express their gratitude to Professor Ibraheim Ahamed Omer and Dr Awad alkareem M Elhassan for revising the draft of the manuscript, and to the staff members who reviewed the questionnaire. They also would like to thank the administrations of the faculties of medicine which participated in the study and the students who responded to the questionnaires.

\section{References}

Bandura A. (1986). Social foundations of thoughts and action: A social cognitive theory, Endewood diffs NJ Prentice hall (abstract).

Crandall SJ., Volk RJ., \& Loemker V. (1993). Medical students' attitude toward providing care to under- served: are we training socially responsible physicians? JAMA, 269(19), 2519-1523.

Dambisya YM. (2003). Career intentions of UNITRA medical students and their perceptions about the future. Education for health, 16(3), 286-297.

David WK., Peter A J., Bouhuij s w., Dauphinee D., McAvoy PA., \& Alexander DA. (1990). Medical career choice: current status of research literature. Teach Learn Med., 2(3), 130-138.

Diwan V., Minj C., Chhari N., \& De Costa A. (2013). Indian medical students in public and private sector medical schools: are motivations and career aspiration different? - studies from Madhya Pradesh, India. BMC medical education, 13, 127. http://dx.doi.org/10. 1186/1472-6920-13-127

Esters LT., \& Bowen BE. (2004). Factors influencing enrollment in an urban agricultural education programme. Journal of career and technical education, 21(1), 25-37. 
Fahal AH. (2007). Medical education in Sudan: its strengths and weaknesses. Medical Teacher, 29, 910-914. http://dx. dio.org/10.1080/01421590 701812991

Farrokhi Khajeh YP., Nedjat S., Mohammadi A., Rad ME., \& Majddzadeh R. (2014). Informed choice of entering medical school and academic success in Iranian medical students. Med Educ, 1-5. http://dx.doi.org/10.3109/0142159x 2014918256

Gillies RA., Warren PR., Messias E., Salazar WH., Wagner PJ., \& Huff TA. (2009). Why a medical career and what makes a good doctor? Beliefs of incoming United States medical students. Education for health, 22(3). Retrieved 17 Dec 2009 from http://www.educationforhealth.net

Kim kyong-jee, Park Jae Hyun, Lee Y-H., \& Choi K. (2013). What is different about medical students interested in non-medical career? BMC Medical Education, 13, 81. http://dx.doi.org/10.1186/1472-6920-13-81

Krumboltz JD., Mitchel AM., \& Jones GB. (1976). A social learning theory of career choice. The counseling psychologist, 6(1), 71-81

Marley J., \& Carman I. (1999). Selecting medical students: A case report of need of change. Med Educ, 33, 455-495

Maudsley G., Williams EMI., \& Taylor CMD. (2007). Junior medical students` notions of a good doctor and related expectation: a mixed methods study. Medical Education, 41(5), 476-486. http://dx.doi.org.10.1111/J1365-2929.2007.02729x

Mc Harg J., Mattick KR., \& Knight L. (2007). Why people apply to medical school? implication for widening participation activities. Med Educ, 41, 815- 821. http://dx.doi.org/10. 1111/J 1365-2923.2007.22798.x

McHugh SM., Corrigan MA., Sheikh A., Broe P., \& Hill ADH. (2011). A study of the factors school -going students considering medical careers. The Surgeon, 9(4), 191-194.

Ministry of Higher Education and Scientific Research. (2008). Directorate general of the public higher education institutions in Sudan. The general administration of research and planning, Khartoum 2008 (in Arabic)

Ministry of Higher Education and Scientific Research. (2008). Directorate general of the private and foreign higher education institutions in Sudan. The general administration of research and planning, Khartoum 2008 (in Arabic)

Ministry of higher education and scientific research. Directorate of admission, evaluation and authentication of certificates. (2013). Directory of admission to the public and private higher education institutions 2013-2014, Khartoum. Retrieved from http://www.admission.gov.sd (in Arabic)

Mitchel AM., L evin AS., \& Krumboltz JD. (1999). Planned happenstance: constructing unexpected career opportunities. Journal of counseling and development, 77, 115- 124.

Sherril W W. (2004). MD/MBA students. An analysis of medical students` career choice. Med Educ Online, 9, 14. Retrieved 23 Nov 2013 from http://www.med-ed-only.org

Vanderveen, K., \& Bold RJ. (2008). Effect of generational composition on the surgical workforce. Archives of Surgery, 143(3), 224-226. 